\title{
Induction of cytokines in different organs after intranasal inoculation of Campylobacter jejuni in mice
}

\author{
Nadia A Al-Banna, Raj Raghupathy and M John Albert ${ }^{*}$
}

\begin{abstract}
Background: Cytokine production and histopathological changes occur in the lungs of mice after intranasal inoculation with Campylobacter jejuni, but the levels of cytokines in different organs to which C. jejuni disseminates have not been studied.

Findings: Adult BALB/c mice were intranasally inoculated with C. jejuni 81-176 (test) or phosphate-buffered saline (control) ( $n=16$ per group). The levels of cytokines in the organs (spleen, liver, and small and large intestines) to which C. jejuni disseminated were measured by ELISA. Two cytokine patterns were observed. First, increased proinflammatory cytokines, TNF-a, IL-1, and IL-2, were followed by anti-inflammatory cytokines, IL-4 and IL-10 in the spleen and large intestine. Second, in the liver and small intestine, there was a predominant production of anti-inflammatory cytokines, IL-4 and IL-10, with some increase in IL-2 levels. In the spleen and intestines, the levels of pro- and anti-inflammatory cytokines were concurrently increased.

Conclusion: Dissemination of $C$. jejuni is associated with the production of different cytokine profiles in different tissues, with the proinflammatory response appearing in the spleen and large intestine at an earlier time point than in the liver and small intestine. The organs produce different cytokine profiles in response to C. jejuni dissemination. These preliminary findings should be confirmed with a study involving a larger group of animals.
\end{abstract}

Keywords: Campylobacter jejuni, Cytokines, Systemic, Mouse lung model

\section{Findings}

\section{Background}

The extraintestinal manifestations of Campylobacter jejuni, an enteropathogenic bacterium [1], are reported in some patients [2]. C. jejuni invades epithelial cells in vitro [3], and can be isolated from the spleen and liver in infected animals $[4,5]$. In vitro studies demonstrated the production of proinflammatory cytokines in C. jejuni-infected monocytic [6], dendritic [7] and intestinal epithelial cell lines [8], peripheral blood mononuclear cells [9] and splenocytes [10]. The association between cytokine production and disease protection/ resolution, suggested in patients [9], was shown by the increased susceptibility of mice deficient in MyD88 or

\footnotetext{
* Correspondence: john@hsc.edu.kw
Department of Microbiology, Faculty of Medicine, Kuwait University, PO Box

* Correspondence: john@hsc.edu.kw 24923, Safat 13110, Kuwait
}

NF-kB to C. jejuni [11,12]. However, cytokine responses after C. jejuni dissemination were not characterised in vivo.

In the current study, we used the mouse lung model to examine whether different tissues produce cytokines after $C$. jejuni disseminates from the primary site of infection. This model was used to study the pathogenesis and immunity of C. jejuni [13-15] and other enteric pathogens [16,17]. Also, we previously studied the histopathological changes and the cytokines produced in the lungs after C. jejuni infection [18], and C. jejuni dissemination to several organs [19]. Though the lung model is an unnatural model for enteric pathogens, it is a relevant model, as the lungs and the gut are part of a common mucosal system and oral infection induces immunity that protects other mucosal sites including the lungs [20]. 


\section{Materials and methods}

A lung model of $C$. jejuni infection was used in adult mice $[18,19]$. The experiments were conducted according to institutional guidelines after ethical committee approval. Briefly, adult BALB/c mice were intranasally inoculated with $\sim 4 \times 10^{9} \mathrm{cfu}$ (colony forming units) of $C$. jejuni strain 81-176 ( $\mathrm{n}=16$, test) or phosphate-buffered saline (PBS, $\mathrm{pH} 7.2)(\mathrm{n}=16$, control). After 1-10 days, blood and several organs (spleen, liver, and small and large intestines) of mice (from 4 mice each from test and control groups sacrificed at each time point) were collected, weighed and placed on ice. The organs were homogenised in PBS using a pestle and mortar under sterile condition in a biosafety cabinet. Homogenates were resuspended in 1\% Triton X-100 (Sigma, St. Louis, MO, USA) on ice and centrifuged at $4^{\circ} \mathrm{C}$ at $19,319 \times g$ for $10 \mathrm{~min}$ in a Beckman J2-MI centrifuge using a JA 20.1 rotor (Beckman, Fullerton, CA, USA). Sera and supernatants were stored at $-80^{\circ} \mathrm{C}$.

Cytokines (TNF- $\alpha$, IL-1, IL-2, IL-4, and IL-10) were assessed in duplicate samples of sera and tissue homogenates using ELISA, according to manufacturer's instructions. Kits were obtained from Endogen (Pierce Biotechnology, Rockford, IL, USA) and Biosource (Biosource International, Invitrogen, Camarillo, CA, USA). Absorbance values were read at $450 \lambda$ using an ELISA reader (Labsystems Multiscan MS, Finland). Cytokine levels were expressed in $\mathrm{pg} / \mathrm{ml}$ of serum, or $\mathrm{pg} / 100 \mathrm{mg}$ of tissue: $(\mathrm{pg} / \mathrm{ml} \times$ volume of homogenate in $\mathrm{ml}) /($ weight in grams $\times 10)$. As the data obtained were not normally distributed, Mann-Whitney $U$ test was used for nonparametric comparison, and the difference was considered significant with $P$ value $\leq 0.05$.

The cytokine production in the lungs and the histopathology of the lungs of these animals have been previously reported $[18,19]$.

\section{Results}

C. jejuni induces proinflammatory cytokines in the spleen and large intestine at an earlier time point than in the liver and small intestine

C. jejuni was isolated from the spleen, liver and serum on day 1 , and from the small and large intestines for up to day 5 post-intranasal inoculation [19]. We observed the production of TNF- $\alpha$, IL-1 and IL-2 in these organs at different time points (Table 1). Initially, the levels of proinflammatory cytokines were increased in the spleen, large intestine and serum. On day $1, T N F-\alpha$ levels were increased by 4-12 fold in all organs, IL- 2 levels were increased in the spleen and IL-1 levels were increased in the sera of test animals compared to those in control animals $(\mathrm{P}<0.05)$. On day 3 , the IL-1 level was increased by 2.5 -fold in the spleen, and on day 5 , the levels of IL-1 and/or IL-2 were significantly increased in the spleen, large intestine and serum of test mice $(\mathrm{P}<0.05)$. However, in the liver and small intestine, the levels of IL-1 and/or IL- 2 were increased only on day $3(\mathrm{P}<0.05)$, and the level of TNF- $\alpha$ was similar to that in controls.

\section{C. jejuni induces anti-inflammatory cytokines in all organs by day 5}

Anti-inflammatory cytokines were most apparent on day 5 , with a 2-fold increase in the IL-4 levels in the spleen, liver, large intestine and serum, and a 2-20 fold increase in the IL-10 levels in the liver, and small and large intestines (Table 2). There was an early rise in the levels of anti-inflammatory cytokines in the spleen and serum, and small intestine on days 1 , and 3 , respectively.

\section{Discussion}

This is the first study to report cytokine responses induced in different organs over an extended period after C. jejuni dissemination (summarised in Table 3). The proinflammatory cytokine response was induced in the spleen and large intestine before the response in the liver and small intestine. For example, the level of TNF$\alpha$ was increased in the spleen, large intestine and serum, but not in the liver and small intestine on day 1 , although the organism was isolated from these tissues [19]. IL-1 levels were increased in the spleen, large intestine and serum on day 3 and/or 5 , but only on day 3 in the liver, and remained unchanged in the small intestine.

We detected cytokines in the serum after intranasal inoculation, as others have found in intraperitoneal or oral models [21,22]. However, the cytokine profile in the serum was not representative of organs. Indeed, the serum IL-1 level on day 1 did not correspond to any organ, and serum levels on day 5 coincided with those in the spleen and large intestine only.

Before cytokine normalisation on day 10, the levels of IL-4 and IL-10 were increased by day 5 . This early increase is difficult to interpret, especially when it coincided with increased proinflammatory cytokine levels, as in the spleen (day 1) or small intestine (day 3). Concurrent pro-and anti-inflammatory cytokine production was noted in an invitro model [8].

Our observations illustrate C. jejuni-induced cytokine responses in different organs, and may reflect cellular responses. The increased TNF- $\alpha$ and IL-1 levels may represent the activation of antigen presenting cells (activated macrophages and dendritic cells), and intestinal epithelial cells in response to C. jejuni, as in in vitro models [6-8,23]. Similarly, the increased IL-2 levels, which control reinfection of C. jejuni in mice [24], may reflect the activation of IL-2 responsive $\mathrm{T}$ cells and/or natural killer cells [25]. Examining the histopathological changes and the influx of cytokine producing cells will further our understanding of this response. In future, a 
Table 1 Levels of proinflammatory cytokines, TNF- $a$, IL-1 and IL-2, in intranasally infected mice with C. jejuni (mean \pm SD)

\begin{tabular}{|c|c|c|c|c|c|c|c|c|c|c|c|c|c|}
\hline \multirow[t]{2}{*}{ Organ } & \multirow[t]{2}{*}{ Group } & \multicolumn{3}{|c|}{ Day 1} & \multicolumn{3}{|c|}{ Day 3} & \multicolumn{3}{|c|}{ Day 5} & \multicolumn{3}{|c|}{ Day 10} \\
\hline & & TNF- $a$ & IL-1 & IL-2 & TNF-a & IL-1 & IL-2 & TNF- $a$ & IL-1 & IL-2 & TNF- $a$ & IL-1 & IL-2 \\
\hline \multirow[t]{2}{*}{ Spleen } & Test & $1042( \pm 32)^{*}$ & $270( \pm 59)$ & $153( \pm 39)^{*}$ & $478( \pm 340)$ & $861( \pm 387)^{*}$ & $181( \pm 16)$ & $114( \pm 16)$ & $1094( \pm 208) *$ & $70( \pm 39)$ & $138( \pm 26)$ & $852( \pm 183)$ & $78( \pm 19)$ \\
\hline & Control & $245( \pm 31)$ & $814( \pm 262)$ & $87( \pm 27)$ & $1045( \pm 57)$ & $319( \pm 89)$ & $105( \pm 51)$ & $218( \pm 65)$ & $717( \pm 62)$ & $170( \pm 92)$ & $182( \pm 16)$ & $1186( \pm 381)$ & $55( \pm 13)$ \\
\hline \multirow[t]{2}{*}{ Large intestine } & Test & $110( \pm 59)^{*}$ & $111( \pm 12)$ & $471( \pm 655)$ & $20( \pm 5)$ & $147( \pm 127)$ & $1634( \pm 918)$ & $13( \pm 3)$ & $161( \pm 40)^{*}$ & $5752( \pm 1251)^{*}$ & $6( \pm 7)$ & $101( \pm 35)$ & ND \\
\hline & Control & $13( \pm 6)$ & $141( \pm 10)$ & $5416( \pm 1057)$ & $109( \pm 61)$ & $144( \pm 59)$ & $1707( \pm 739)$ & $15( \pm 11)$ & $62( \pm 47)$ & $2216( \pm 705)$ & $16( \pm 1)$ & $159( \pm 44)$ & ND \\
\hline \multirow[t]{2}{*}{ Liver } & Test & $186( \pm 17)$ & $50( \pm 21)$ & $256( \pm 129)$ & $4581( \pm 4244)$ & $133( \pm 33)^{*}$ & $1209( \pm 745)^{*}$ & $3860( \pm 1000)$ & $118( \pm 34)$ & $389( \pm 69)$ & ND & $126( \pm 7)$ & $64( \pm 22)$ \\
\hline & Control & $4567( \pm 1992)$ & $73( \pm 25)$ & $718( \pm 297)$ & $4425( \pm 992)$ & $79( \pm 26)$ & $458( \pm 116)$ & $4183( \pm 273)$ & $142( \pm 72)$ & $366( \pm 102)$ & ND & $148( \pm 31)$ & $55( \pm 8)$ \\
\hline \multirow[t]{2}{*}{ Small intestine } & Test & $7( \pm 6)$ & $12( \pm 9)$ & $2483( \pm 286)$ & $11( \pm 2)$ & $6( \pm 0)$ & $2063( \pm 428)^{*}$ & $6( \pm 2)$ & $12( \pm 2)$ & $5427( \pm 756)$ & $13( \pm 3)$ & $4( \pm 1)$ & $3640( \pm 1737)$ \\
\hline & Control & $16( \pm 13)$ & $142( \pm 37)$ & $7352( \pm 1909)$ & $11( \pm 2)$ & $11( \pm 6)$ & $830( \pm 335)$ & $11( \pm 1)$ & $112( \pm 25)$ & $5012( \pm 828)$ & $10( \pm 5)$ & $2( \pm 1)$ & $6603( \pm 379)$ \\
\hline \multirow[t]{2}{*}{ Serum } & Test & $101( \pm 9)^{*}$ & $55( \pm 13)^{*}$ & $8( \pm 0)$ & $28( \pm 39)$ & $27( \pm 2)$ & $8( \pm 0)$ & $76( \pm 54)$ & $23( \pm 4)^{*}$ & $8( \pm 0)$ & $45( \pm 39)$ & $23( \pm 1)$ & $8( \pm 0)$ \\
\hline & Control & $29( \pm 14)$ & $8( \pm 9)$ & $8( \pm 0)$ & $100( \pm 5)$ & $16( \pm 11)$ & $8( \pm 0)$ & $43( \pm 36)$ & $3( \pm 0)$ & $8( \pm 0)$ & $85( \pm 14)$ & $28( \pm 3)$ & $8( \pm 0)$ \\
\hline
\end{tabular}

* Indicates significant difference $(P \leq 0.05)$ in values between test and control mice; ND, not done. 
Table 2 Levels of anti-inflammatory cytokines, IL-4 and IL-10, in intranasally infected mice with C. jejuni (mean \pm SD)

\begin{tabular}{|c|c|c|c|c|c|c|c|c|c|}
\hline \multirow[t]{2}{*}{ Organ } & \multirow[t]{2}{*}{ Group } & \multicolumn{2}{|c|}{ Day 1} & \multicolumn{2}{|c|}{ Day 3} & \multicolumn{2}{|c|}{ Day 5} & \multicolumn{2}{|c|}{ Day 10} \\
\hline & & IL-4 & IL-10 & IL-4 & IL-10 & IL-4 & IL-10 & IL-4 & IL-10 \\
\hline \multirow[t]{2}{*}{ Spleen } & Test & $15277( \pm 6630)$ & $314( \pm 32) *$ & $22824( \pm 3489)$ & $326( \pm 125)$ & $40284( \pm 10363)^{*}$ & $364( \pm 38)$ & $9509( \pm 3368)$ & $190( \pm 129)$ \\
\hline & Control & $23230( \pm 3829)$ & $239( \pm 34)$ & $16706( \pm 7430)$ & $354( \pm 54)$ & $21164( \pm 1355)$ & $433( \pm 201)$ & $18770( \pm 4750)$ & $130( \pm 49)$ \\
\hline \multirow[t]{2}{*}{ Large intestine } & Test & $1( \pm 1)$ & $2( \pm 0)$ & $4( \pm 3)$ & $10( \pm 11)$ & $31( \pm 31)^{*}$ & $103( \pm 113)^{*}$ & $5( \pm 1)$ & $12( \pm 3)$ \\
\hline & Control & $3( \pm 1)$ & $13( \pm 10)$ & $6( \pm 5)$ & $37( \pm 6)$ & $6( \pm 3)$ & $13( \pm 12)$ & $8( \pm 2)$ & $6( \pm 4)$ \\
\hline \multirow[t]{2}{*}{ Liver } & Test & $4960( \pm 5721)$ & $90( \pm 14)$ & $15856( \pm 15787)$ & $122( \pm 21)$ & $13820( \pm 3241)^{*}$ & $276( \pm 45)^{*}$ & ND & $216( \pm 14)$ \\
\hline & Control & $20819( \pm 6306)$ & $148( \pm 23)$ & $5033( \pm 3280)$ & $147( \pm 40)$ & $6380( \pm 2833)$ & $138( \pm 45)$ & ND & $211( \pm 68)$ \\
\hline \multirow[t]{2}{*}{ Small intestine } & Test & $15( \pm 10)$ & $2( \pm 0)$ & $31( \pm 4)^{*}$ & $7( \pm 7)$ & $19( \pm 10)$ & $23( \pm 15)^{*}$ & $11( \pm 3)$ & $11( \pm 9)$ \\
\hline & Control & $23( \pm 11)$ & $2( \pm 0)$ & $15( \pm 9)$ & $8( \pm 5)$ & $23( \pm 11)$ & $2( \pm 1)$ & $22( \pm 5)$ & $6( \pm 4)$ \\
\hline \multirow[t]{2}{*}{ Serum } & Test & $786( \pm 194)^{*}$ & $339( \pm 70)$ & $239( \pm 85)$ & $152( \pm 118)$ & $435( \pm 70)^{*}$ & $48( \pm 31)$ & $335( \pm 108)$ & $113( \pm 70)$ \\
\hline & Control & $323( \pm 29)$ & $236( \pm 118)$ & $1690( \pm 123)$ & $484( \pm 321)$ & $284( \pm 78)$ & $304( \pm 157)$ & $409( \pm 123)$ & $323( \pm 128)$ \\
\hline
\end{tabular}

* Indicates significant difference $(P \leq 0.05)$ in values between test and control mice; ND, not done.

large sample size of animals should be used to avoid the inconsistencies we observed in the levels of some cytokines, for example, reduced levels of IL-1 in the small intestine. Other cytokines (IFN- $\gamma$, IL-6, IL-17 and IL-22) and other strains of $C$. jejuni and other campylobacter species should also be studied.

Surprisingly, the colonisation status did not fully correlate with the cytokine profile (Table 3). Proinflammatory cytokine profiles varied between the different organs that had $C$. jejuni on day 1 , for example, the spleen and large intestine, in contrast to the liver and small intestine. The increased anti-inflammatory cytokines and the isolation of C. jejuni from the small and large intestines coincided, while the production of IL-1 in the spleen, liver and serum continued beyond bacterial clearance. It is unclear if the presence of $C$. jejuni in the intestine on days 3 and 5 would provide a source of virulence factors that affect the spleen.

\section{Conclusion}

This is the first study to demonstrate the induction of cytokine responses by different organs in mice over an extended period of time after intranasal inoculation with C. jejuni. The cytokine profiles of these organs differed. Some organs produced cytokines even after bacterial clearance. These findings illustrate the dynamic nature of cytokine production in different organs that can respond to $C$. jejuni dissemination, possibly reflecting their immune status. Future work should examine other cytokines and determination of cellular sources of all cytokines using a larger sample size of mice.

Table 3 Summary of observed cytokine profiles and bacterial dissemination in intranasally infected mice with C. jejuni

\begin{tabular}{|c|c|c|c|c|c|}
\hline Organ & Observation & Day 1 & Day 3 & Day 5 & Day 10 \\
\hline \multirow[t]{3}{*}{ Spleen } & Proinflammatory cytokine & TNF-a, IL-2 & IL-1 & $\mathrm{IL}-1$ & - \\
\hline & Anti-inflammatory cytokine & IL-10 & - & - & - \\
\hline & C. jejuni isolated & Yes & No & No & ND \\
\hline \multirow[t]{3}{*}{ Large intestine } & Proinflammatory cytokine & TNF-a & - & $\mathrm{IL}-1, \mathrm{IL}-2$ & - \\
\hline & Anti-inflammatory cytokine & - & - & IL-4, IL-10 & - \\
\hline & C. jejuni isolated & Yes & Yes & Yes & ND \\
\hline \multirow[t]{3}{*}{ Liver } & Proinflammatory cytokine & - & $\mathrm{IL}-1, \mathrm{IL}-2$ & - & - \\
\hline & Anti-inflammatory cytokine & - & - & IL-4, IL-10 & - \\
\hline & C. jejuni isolated & Yes & No & No & ND \\
\hline \multirow[t]{3}{*}{ Small intestine } & Proinflammatory cytokine & - & IL-2 & - & - \\
\hline & Anti-inflammatory cytokine & - & IL-4 & IL-10 & - \\
\hline & C. jejuni isolated & Yes & Yes & Yes & ND \\
\hline \multirow[t]{3}{*}{ Serum } & Proinflammatory cytokine & TNF-a, IL-1 & - & $\mathrm{IL}-1$ & - \\
\hline & Anti-inflammatory cytokine & IL-4 & - & IL-4 & - \\
\hline & C. jejuni isolated & Yes & No & No & ND \\
\hline
\end{tabular}




\section{Competing interests}

The authors declare that they have no competing interests.

\section{Authors' contributions}

NA carried out the experiments and wrote the manuscript. RR participated in experimental design and revised the manuscript. MJA supervised the experimental work and revised the manuscript. All authors read and approved the final manuscript.

\section{Acknowledgement}

This study was partly supported by the College of Graduate Studies, Kuwait University, Kuwait.

Received: 23 November 2012 Accepted: 6 December 2012 Published: 17 December 2012

\section{References}

1. Blaser MJ: Epidemiologic and clinical features of Campylobacter jejuni infections. J Infect Dis 1997, 176(Suppl 2):S103-S105.

2. Skirrow MB, Blaser MJ: Clinical aspects of Campylobacter jejuni infection. In Campylobacter. 2nd edition. Edited by Nachamkin I, Blaser MJ. Washington DC: American Society of Microbiology; 2000:69-88.

3. Byrne CM, Clyne M, Bourke B: Campylobacter jejuni adhere to and invade chicken intestinal epithelial cells in vitro. Microbiology 2007, 153:561-569.

4. Boukraa L, Messier S, Robinson Y: Isolation of Campylobacter from livers of broiler chickens with and without necrotic hepatitis lesions. Avian Dis 1991, 35:714-717.

5. Vuckovic D, Abram M, Doric M: Primary Campylobacter jejuni infection in different mice strains. Microb Pathog 1998, 24:263-268.

6. Jones MA, Totemeyer S, Maskell DJ, Bryant CE, Barrow PA: Induction of proinflammatory responses in the human monocytic cell line THP-1 by Campylobacter jejuni. Infect Immun 2003, 71:2626-2633.

7. Hu L, Bray MD, Osorio M, Kopecko DJ: Campylobacter jejuni induces maturation and cytokine production in human dendritic cells. Infect Immun 2006, 74:2697-2705.

8. Al-Salloom FS, Al Mahmeed A, Ismaeel A, Botta GA, Bakhiet M: Campylobacter-stimulated INT407 cells produce dissociated cytokine profiles. J Infect 2003, 47:217-224.

9. Tribble DR, Baqar S, Scott DA, Oplinger ML, Trespalacios F, Rollins D, Walker RI, Clements JD, Walz S, Gibbs P, Burg EF 3rd, Morgan AP, Applebee L, Bourgeois AL: Assessment of the duration of protection in Campylobacter jejuni experimental infection in humans. Infect Immun 2009, 78:1750-1759.

10. Pancorbo PL, de Pablo MA, Ortega E, Puertollano MA, Gallego AM, Alvarez de Cienfuegos G: Potential intervention of Campylobacter jejuni in the modulation of murine immune response. Curr Microbiol 2001, 43:209-214.

11. Rathinam VA, Appledorn DM, Hoag KA, Amalfitano A, Mansfield LS: Campylobacter jejuni-induced activation of dendritic cells involves cooperative signaling through toll-like receptor 4 (TLR4)-MyD88 and TLR4-TRIF axes. Infect Immun 2009, 77:2499-2507.

12. Fox JG, Rogers AB, Whary MT, Ge Z, Taylor NS, Xu S, Horwitz BH, Erdman SE: Gastroenteritis in NF-kappaB-deficient mice is produced with wild-type Campylobacter jejuni but not with $C$. jejuni lacking cytolethal distending toxin despite persistent colonization with both strains. Infect Immun 2004, 72:1116-1125.

13. Baqar S, Applebee LA, Bourgeois AL: Immunogenicity and protective efficacy of a prototype Campylobacter killed whole-cell vaccine in mice. Infect Immun 1995, 63:3731-3735.

14. Baqar S, Applebee LA, Gilliland TC Jr, Lee LH, Porter CK, Guerry P: Immunogenicity and protective efficacy of recombinant Campylobacter jejuni flagellum-secreted proteins in mice. Infect Immun 2008, 76:3170-3175.

15. Baqar S, Bourgeois AL, Applebee LA, Mourad AS, Kleinosky MT, Mohran Z, Murphy JR: Murine intranasal challenge model for the study of Campylobacter pathogenesis and immunity. Infect Immun 1996, 64:4933-4939.

16. van de Verg LL, Mallett CP, Collins HH, Larsen T, Hammack C, Hale TL: Antibody and cytokine responses in a mouse pulmonary model of Shigella flexneri serotype 2a infection. Infect Immun 1995, 63:1947-1954.

17. Fullner KJ, Boucher JC, Hanes MA, Haines GK 3rd, Meehan BM, Walchle C, Sansonetti PJ, Mekalanos JJ: The contribution of accessory toxins of Vibrio cholerae $01 \mathrm{El}$ Tor to the proinflammatory response in a murine pulmonary cholera model. J Exp Med 2002, 195:1455-1462.

18. Al-Banna N, Raghupathy R, Albert MJ: Correlation of proinflammatory and anti-inflammatory cytokine levels with histopathological changes in an adult mouse lung model of Campylobacter jejuni infection. Clin Vaccine Immunol 2008, 15:1780-1787.

19. Al-Banna NA, Junaid TA, Mathew TC, Raghupathy R, Albert MJ: Histopathological and ultrastructural studies of a mouse lung model of Campylobacter jejuni infection. J Med Microbiol 2008, 57:210-217.

20. Kiyono H: Mucosal immune system: close encounter in the uncharted world of immunology. Ophthalmologica 2001, 215(Suppl 1):22-32.

21. Smith CK, Abuoun M, Cawthraw SA, Humphrey TJ, Rothwell L, Kaiser P, Barrow PA, Jones MA: Campylobacter colonization of the chicken induces a proinflammatory response in mucosal tissues. FEMS Immunol Med Microbiol 2008, 54:114-121.

22. Abram $M$, Vu kovic D, Wraber B, Doric M: Plasma cytokine response in mice with bacterial infection. Mediators Inflamm 2000, 9:229-234.

23. Pancorbo PL, de Pablo MA, Ortega E, Gallego AM, Alvarez C, Alvarez de Cienfuegos G: Evaluation of cytokine production and phagocytic activity in mice infected with Campylobacter jejuni. Curr Microbiol 1999, 39:129-133.

24. Baqar S, Pacheco ND, Rollwagen FM: Modulation of mucosal immunity against Campylobacter jejuni by orally administered cytokines. Antimicrob Agents Chemother 1993, 37:2688-2692.

25. Mori S, Jewett A, Cavalcanti M, Murakami-Mori K, Nakamura S, Bonavida B: Differential regulation of human NK cell-associated gene expression following activation by IL-2. IFN-alpha and PMA/ionomycin. Int J Oncol 1998, 12:1165-1170.

doi:10.1186/1757-4749-4-23

Cite this article as: Al-Banna et al.: Induction of cytokines in different organs after intranasal inoculation of Campylobacter jejuni in mice. Gut Pathogens 2012 4:23.

\section{Submit your next manuscript to BioMed Central and take full advantage of:}

- Convenient online submission

- Thorough peer review

- No space constraints or color figure charges

- Immediate publication on acceptance

- Inclusion in PubMed, CAS, Scopus and Google Scholar

- Research which is freely available for redistribution

Submit your manuscript at www.biomedcentral.com/submit
C BioMed Central 